\title{
A Step Toward Workplace Obesity Prevention: Evaluation of Weight Management Program for Hospital-based Health Care Providers
}

\author{
Choy HK ${ }_{a}$, Chu HK Oliva $b$, Keung WY ${ }_{c}$, Lim B ${ }_{d}$, Tang PY Winnie $e_{e}$, Nikki Coghill ${ }_{f}$ \\ a. Doctoral Student, Department of Health, University of Bath; b. Dietitian, Department of Dietetics, Yan Chai Hospital; c. \\ Advanced Practice Nurse, Department of Surgery, Yan Chai Hospital; d. Senior Medical Officer, Yan Chai Hospital Hong Kong; \\ e. Professional Consultant, The Chinese University of Hong Kong; f. Lecturer, Department of Health, University of Bath
}

\begin{abstract}
Background: Obesity is a worldwide problem. Healthy workplace and lifestyle are crucial in preventing obesity. A workplace weight management program could create a culture of health and facilitate weight control among health care providers. The present study aims to describe and evaluate the health outcomes of the interaction of professional practice and organizational infrastructure. Method: The hospital-based weight management program was an eight-week pilot randomized controlled study for obese health care providers. The primary outcomes were body weight and body mass index. The secondary outcomes included serum fasting glucose, fasting cholesterol, triglyceride, high- and low-density lipoprotein, body fat percentage, body mass, and quality of life. The RE-AIM framework was used to examine the intervention's reach, effectiveness, adoption, implementation and maintenance at individual and organizational levels. Results: The program successfully attained the target population. Health care providers demonstrated short-term weight loss and decreased serum fasting cholesterol level after completing the program. The excellent retention rate $(95 \%)$ of the study suggested that the participants were well-engaged in self-weight management. The program was implemented with adequate resource and support from the health organization. The organization may consider continuing the program in view of its long-term benefits to health care providers. Conclusion: Supportive organizational structure and culture enhanced professional practice and improved the health outcomes of the hospital-based weight management program participants.
\end{abstract}

Key words: Organization, Workplace, Weight management, Professional practice, RE-AIM

\section{INTRODUCTION}

Workplace obesity is a serious challenge to health care professionals. With increasing weight, the prevalence of chronic diseases such as hypertension, dyslipidemia, and cardiovascular disorders also increases [1]. Obesity is not only an individual health hazard but also a potential organizational problem. This condition is associated with substantially increased rates of absenteeism in an organization [2]. Workers spend almost one-third of a day in the workplace. Thus, the workplace is considered as an ideal setting for health promotion, such that an effective workplace health promotion is urged to address the problem of workplace obesity.

World Health Organization (WHO) defines a healthy workplace as "A place where workers and managers collaborate to use a continuous improvement process to protect and promote the health, safety, and wellbeing of all workers" [3]. Workplace health promotion comprises elements of health risks assessment, counseling, blood pressure measurement, body mass index (BMI) measurement, waist circumference measurement, skinfold testing, or blood testing for serum cholesterol concentration. Occupational health nurses [4] employed by the organization lead workplace health promotion programs, and they assess, plan, implement, and evaluate the program. The effectiveness of health promotion programs is evaluated by individual biometric characteristics. Organizational factors, such as organizational culture, organization leadership, and organization resources, may not be considered as the issues affecting the success of a workplace health promotion program. Meanwhile, "Ad-hoc health promotion programs" show limited long-term benefits for individuals and organizations [5]. Instead, a well-structured workplace health promotion program should be a part of the organizational culture.

Workplace health promotion should not only be initiated by employers but also by the employees of an organization. Regardless of how the program is launched, it would encounter potential barriers from different stakeholders. At the individual level, low motivation, lack of time, unfavorable work schedule, inconvenient location, cost, and poor self-perceived health status are barriers [6] of participating in a health promotion program. At the broad organizational view, the promotion and maintenance of the program are challenged by lack of occupational safety and health infrastructure, negative perception of occupational health requirements and benefits, limited relevant skills and qualifications, inadequate cooperation between key stakeholders, perceived financial investment, and misconception of benefits to the organization [7]. All these factors would limit the participation rate, engagement, and effectiveness of a workplace health promotion program. Thus, extensive planning is vital to successfully implement a workplace health promotion program.

To date, limited research is available on how professional practice and organizational infrastructure interrelate to achieve a high quality workplace health promotion program. First, this paper reviews the literature on the impacts of the organizational factors in professional practice. Second, the RE-AIM model [8] evaluates the different 
dimensions of the workplace health promotion program at individual and organizational levels. Finally, suggestions for a successful workplace health promotion program are presented.

\section{LITERATURE REVIEW}

\section{Professionalism}

Professionalism may be modified corresponding to organization policy. The concept of professionalism is originally intended for the stability and civility of a social system [9]. The following are five key elements of professionalism: 1. practitioner's reliance on a professional organization as a major reference point; 2 . belief in public service; 3 . belief in self-regulation and colleague control; 4 . sense of calling to a specific line of work; and 5. individual autonomy in decision making [10]. After over half a century, these descriptions could still provide insights into why professionalism and organizations are intrinsically conflicting. Historically, professional organizations entitle professionals with autonomy and authority over their working practices [11]. Health professionals practice the standard care described by professional organizations. However, the practice code issued by professional organizations may not always be consistent with the organization's mission. For example, would you accept a refusal to blood transfusions for a trauma patient who is a Jehovah's Witness? Would you refuse to offer medical consultation to an uninsured patient without money to pay the bill? If health professionals work for a health organization, the decision should rely not only on the professional code but also on the health organization policy. Thus, the ability of health professionals to practice their profession effectively and ethically is influenced by the working environment created by organizations.

\section{Organizational infrastructure}

Organizational infrastructure is "the underlying foundation or basic framework through which clinical care is delivered and supported" [12]. The core elements of organizational infrastructure include organizational culture and leadership.

According to Robbins \& Coulter, organizational culture refers to the shared values, beliefs, or perceptions held by employees within an organization [13]. Organizational leadership is "the ability of an individual to influence, motivate, and enable others to contribute toward the effectiveness and success of organizations of which they are members" [14]. Traditionally, organizational leadership interacts with organizational culture to enhance the effectiveness of organizational performance [15]. Organizational leaders create a vision and lead the achievement of common goals. In this sense, an organizational leader shapes the culture of subordinates, and with time, organizational leadership is shaped by culture. Despite the dynamic relationship between organizational leadership and culture, the effectiveness of an organization can be maintained. Organizational leadership can be integrated between health professionals and an organization when both share similar values and expectations toward quality of care. However, organizations do not bring diverse points of view into the decision-making process [16]. Under this situation, organizational infrastructure may conflict with professional practice and affect outcome quality.

\section{Quality of Care}

Positive professional and organizational interaction results in high quality health care. Health care professional practice determines the quality of provided care [17]. Guidelines, protocols, and audits established by health care professionals aim to ensure high standard of care. However, these principles of care may not be applied properly unless they are integrated into organizational policy. For instance, the principle of drug administration "Three Checks and Five Rights" [18] adopted by a nursing professional is used to eliminate medication error and enhance quality of care. A nursing professional may focus on safety issues, whereas an administrative manager may consider the efficiency of drug administrative procedure. Poor communication between organizational boards and health care professionals hinder the improvement of quality care [19]. Quality of care is the performance index for both health organization and health care professional; hence, integrated quality management should be emphasized in the future.

The literature review consistently indicated that professional practice is bound by organizational constraints. Professionalism changes the response to organization policy. A collaborative working model should be advocated between professionals and organizations to achieve high quality outcomes that satisfy different organizational shareholders.

\section{AIM}

This paper aims to evaluate and describe how professional and organizational issues affect the implementation quality of a workplace weight management program for health care providers in a hospital setting.

\section{OBJECTIVES}

The research objectives are as follows:

- To describe the evaluation process of a workplace weight management program;

- To explore the process of change in the implementation of a workplace weight management program;

- To identify the factors that facilitated the implementation of a workplace weight management program;

- To identify the barriers in implementing a workplace weight management program;

- To assess how change in practice affects professional, organizational, and quality issues in a practice setting. 


\section{METHODOLOGY}

A hospital-based weight management program was piloted in a regional hospital in Hong Kong in line with the health care providers' view of well-being as crucial to high quality patient care. Unlike an "off-the-shelf" program offered by a vendor, this innovative weight management program was initiated by health care professionals in the same hospital.

This eight-week pilot randomized controlled study included participants from the overweight health care providers in a regional hospital in Hong Kong. A total of 44 participants were recruited in this study, and 42 participants completed the study. Two participants were excluded from the study because of missing data on fasting glucose and lipid profile. Participants were randomly assigned to either intervention $(n=20)$ or control $(n=22)$ group. Participants in both groups received individual nutrition counseling and nutrition pamphlets, whereas only the intervention group participants were provided with mobile phone-based interventions. The primary outcomes were body weight and BMI. The secondary outcomes were fasting glucose, fasting cholesterol, triglyceride, high- and low-density lipoprotein (HDL; LDL), body fat percentage, quality of life, and lifestyle pattern.

\section{EVALUATION APPROACH}

The RE-AIM evaluation framework [8] was applied to address the impacts of practice change on professionalism and organizational infrastructure. Glasgow et al. [8] developed this framework, which has been utilized to plan, evaluate, and report various health promotions and disease management programs. The core dimensions of the framework include reach, effectiveness, adoption, implementation, and maintenance. However, this evaluation explores the interrelationship between professional practice and organizational infrastructure, rather than focusing only on objective health outcomes.

Organizational development theory [20] was used as the theoretical framework in the evaluation report. The theory consists of three components, namely, organizational climate, culture, and capacity. This theory has been used to improve organizational effectiveness. For health care organizations, organizational effectiveness may be gauged in terms of health care quality. Thus, change in organizational climate, culture, or capacity may affect individual behavior and health care quality within the organization. This theory emphasizes that effective organizational change depends on individual and organization cooperation [21]. This evaluation report will demonstrate how organizational issues affect individual health condition.

\section{EVALUATION RESUlts}

\section{A. Reach}

Reach refers to the participation rate and representation of participants. A total of 2230 employees in the study site and $70 \%$ of them were potential participants (health care providers). In addition, $38.8 \%$ potential participants were overweight and eligible to participate in the weight management program. A total of 44 participants were recruited in this study but only 42 participants completed the program. The participants represented $7.2 \%$ of the overall overweight health care providers in the study site. They were either obese $(55 \%)$ or overweight $(45 \%)$, and those with higher BMI were more likely to participate in the program. The excellent retention rate $(95 \%)$ of the study suggests that the participants were interested in weight management.

\section{B. Effectiveness}

Effectiveness refers to the behavioral change, impact on quality of life, and outcome of the intervention. The primary outcomes were body weight and BMI. The secondary outcomes were serum fasting glucose, fasting cholesterol, triglyceride, HDL and LDL, body fat percentage, body mass, level of healthy lifestyle, and quality of life. Compared with the control group, the intervention group showed approximately $0.98 \mathrm{~kg}$ weight reduction in 2 months. The intervention group participants also demonstrated clinically significant improvements in BMI and serum cholesterol and HDL levels. However, no improvements in body fat percentage and body mass were observed in both intervention and control groups. The intervention group participants who received mobile phone text messages were more likely to lose weight than those in the control group.

The quality of life among participants was evaluated through a Short form Quality of Life (SF-12v2) [23] with Physical and Mental Component Scores (PCS; MCS). The mean scores of participants improved from 42.83 to 49.74 for PCS and from 53.42 to 55.51 for MCS in the intervention group. The quality of life of the participants was satisfactory after the program.

The healthy lifestyle level of the participants was evaluated by Health Promoting Lifestyle Pattern II [24] that consisted of six subscale scores. The highest subscale mean score was obtained for individual relations, whereas the lowest subscale mean score was derived for health responsibility. The subscale mean scores of nutrition, health responsibility, and physical activity improved in the intervention group. The healthy lifestyle level of the participants improved after the program. 


\section{Adoption}

Adoption is the level of involvement in individual and organizational levels. The mean age of the participants was 46 years old, and $18 \%$ of the participants were male, whereas $82 \%$ were female. Significant gender differences were observed, and female participants were more likely to participate in the weight management program. The excellent retention rate $(95 \%)$ of the study suggested that the participants were interested in the weight management program.

The organization's support is evidenced in various aspects throughout the hospital-based weight management program. First, the program was free of charge and funded by the hospital. Eligible health care providers could voluntarily join the program with no financial incentive or penalty. Moreover, the program activities were conducted in the study site. Therefore, the participants could attend the workshop without leaving the workplace. The weight management interventions were provided in a relatively flexible schedule to address the shift work needs of some participants.

\section{Implementation}

Implementation is the delivery of interventions. All participants were randomly assigned to either intervention or control group. Both groups received face-to-face nutritional education session provided by a registered dietitian. The educational session included nutritional knowledge on etiology, clinical manifestation, treatment modality of obesity, food selection, and food labeling. The intervention group participants received tailored weight management intervention, including individual nutrition counseling, nutrition pamphlets, telephone counseling, and smart phone text messages within eight weeks. The control group participants only received individual nutrition counseling and nutrition pamphlets. The biometric characteristics, as well as the blood samples of fasting glucose and fasting cholesterol were measured at the baseline and in the eight-week follow up period.

Focus group revealed that over $90 \%$ of the participants reported that the workplace weight management program enhanced their knowledge and compliance to healthy eating. However, around $40 \%$ of the participants reported that the frequency of dietitian consultation should increase.

The organization plays an important role in facilitating program implementation. First, the participation of senior-level managers directly motivated health care providers to join the program. Second, an effective communication among multi-level managers encouraged good coordination among health professionals. For instance, the role and responsibility of health professionals were described as follows: the registered dietitian and advanced practice nurse responsible for recruitment and implementation, the medical officer backed up the abnormal blood results counseling and the pathologist responsible for blood specimens testing. Third, the organization delegated the autonomy and authority of the principle investigator (PD student) to prepare, conduct, and evaluate the workplace weight management program, thereby facilitating the flexibility of program refinement.

\section{E. Maintenance}

Maintenance refers to the sustainability of change in individual and organizational levels. Qualitative data from the focus group revealed that all participants were satisfied with the workplace weight management program. Almost all participants expressed that they would follow the dietary advices to achieve healthy eating.

At organization level, the success of the pilot Nutritional Wellness Program may stimulate the interest of high level management to sustain the wellness program for hospital employees.

Table 1 presents the dimensions of the RE-AIM applied to the hospital-based weight management program.

\section{DISCUSSION}

Public service hospitals are complex professional bureaucracies comprising of varied health care professionals. These professionals receive relative authority and autonomy in their practice [11]. Initiating change in both health care professionals and health organizations especially in a hospital setting is difficult. This evaluation report provides insights into how health care professionals interact with organizational infrastructures to create a successful workplace weight management program.

This hospital-based weight management program succeeded in reaching overweight or obese health care providers. A total of 44 overweight health care providers were recruited from the study site. The response rate was unsatisfactory despite the poster, flyers, and invitation emails sent to various departments and health care providers. The low participation rate of $7.2 \%$ of the target participants may be attributed to the insufficient time for program promotion. The program was launched immediately after obtaining ethical approval from the Institutional Review Boards of Hospital Authority. Thus, health care providers may not have been aware of the program on such short notice. Poor self-perceived health status is the common individual barrier for participation. Participants may not perceive obesity as a 
problem that requires intervention. To refine the reach of the program, its organizer can consider including a workplace health promotion program in the hospital annual meeting agenda.

\section{Impact of practice change on professionalism}

This innovative weight management program was initiated and implemented by health professionals in the study site. Health professionals experienced role changes throughout the program. Instead of providing professional service to clients, health professionals should develop the organizational capacity and assume the roles of organizer, leader, communicator, and facilitator for the program. For instance, health professionals acted as an organizer responsible for preparing the research proposal, attending the Institutional Review Boards interview, liaising managers at all levels, scheduling all program interventions, seeking funding, allocating resources, and managing the program. All these tasks are not part of the typical professional practice of these health professionals.

For the organizer role, health professionals performed particularly well in scheduling program activities. They recognized that the shift work was a unique participation barrier among hospital-based health care providers. Thus, they provided relative flexible assessment and consultation sections for health care providers. The focus group discussion revealed that the flexible schedule was appreciated by all participants. The program was smoothly launched with good communication among health professionals. All weight management interventions were implemented by health professionals as planned. Participants in both intervention and control groups demonstrated clinically significant weight loss. The discussion also showed that the majority of participants would not only follow the dietary advice suggested by dietitian but also take responsibility for their own health after the program.

For the professional practice pattern, health professionals did not provide service to participants in one-toone mode. As health promoters, they broadened the scope of professional service to a group of target participants. They collaborated with other professionals and delivered services with technology. For example, this program involved a medical professional responsible for abnormal blood result counseling. Mobile phones were used as delivery tools to provide effective and efficient service to target participants.

Impact of practice change on organizational infrastructure

Workplace weight management program affects organizational financial resource, leadership, and culture. This weight management program was supported by "Hospital Donation Fund" from the hospital, which indicated that the organization supported the health-promoting activities for the employees. The program interventions included health assessment, dietitian consultation, blood specimen testing, and mobile-phone interventions. No fees were collected for the weight management interventions. As "lack of money" is a common individual barrier, the free-of-charge services of the program motivated health care providers to participate in the weight management program.

Organizational leadership launched the first weight management program, which was new to all hospital employees. The vision of the organization is "Healthy people, Happy staff, Trusted by the Community," and thus, the organizational leader aimed to ensure that employees were happy and motivated in their work. According to Kouzes and Posner [25], leadership is about spurring a shared vision and modeling the way for the followers. The organizational leader succeeded in arousing the health and well-being awareness of employees through the program, which increased their working morale.

Organizational culture and leadership together achieved the vision and mission of the organization. All managers actively committed to the promotion of the weight management program. The participation of the senior-level managers in the weight management program influenced the attitudes and behavior of health care providers. Health care providers were motivated to participate in the program as the positive environment made them feel safe and comfortable. A culture of health was created at the end of the program.

\section{Impact of practice change on quality of care}

The workplace weight management program significantly affected the health and well-being of the health care providers. The biometric outcomes of health care providers in intervention and control groups demonstrated clinically significant weight loss. The mean weight of the participants changed from baseline to -0.98 and $-0.31 \mathrm{~kg}$ in the intervention and control groups after eight weeks. The focus group interview revealed that the majority of participants not only followed the dietary advice suggested by dietitian but also took responsibility for their own health after the program

The health and well-being of health care providers are critical for high quality care [26-27]. The study period of this weight management program is only 8 weeks; hence, we may not expect the difference in quality of care delivered. However, healthy health care providers are likely to perform well in their workplace.

\section{Strengths and weakness}

The use of RE-AIM framework allows the evaluation of the interventions across levels including participants, middle level management, and top level management within the health organization. Aside from the research outcomes, several dimensions of the program were evaluated at individual and organization levels. Organizational development theory provided an analytical backdrop to assess the performance and construction of the organization. The excellent retention rate $(95 \%)$ of the study suggested that 
participants were well-engaged in self-weight management. However, the minimal sample size and single-centered study limited the generalization of the findings to other populations and work settings.

\section{CONCLUSION}

The result of the evaluation report is consistent with organizational development theory. Supportive organizational environment can optimize professional practice and promote positive health outcomes. The RE-AIM framework can be used as a yardstick to plan, implement, evaluate and report wellness programs in a workplace setting. This research can be considered as a first step toward workplace health promotion in a hospital setting. However, the high quality of well-being among health care providers cannot be cultivated by one single step. This evaluation report could serve as a road map for continuous quality improvement.

\section{ACKNOWLEDGEMENT}

This research study received support from the Hospital Donation Fund from Yan Chai Hospital, Hong Kong. This paper was presented in the 6th Global Health Care Conference 2017, Singapore. 
TABLE I.

\begin{tabular}{|c|c|c|c|c|}
\hline $\begin{array}{l}\text { RE-AIM } \\
\text { dimension }\end{array}$ & Definition & Intervention components & Data source & $\begin{array}{l}\text { Data } \\
\text { Collection }\end{array}$ \\
\hline Reach & $\begin{array}{l}\text { Participation rate of the target } \\
\text { population }\end{array}$ & $\begin{array}{l}\text { Individual level: } \\
\text { Flyers, application forms, and details of } \\
\text { the wellness program to all hospital } \\
\text { employee e-mail accounts } \\
\text { Organizational level: posters and } \\
\text { promotion of the wellness program in } \\
\text { various departments of the hospital }\end{array}$ & $\begin{array}{l}\text { Enrolment } \\
\text { record; follow up } \\
\text { survey; focus group } \\
\text { interview }\end{array}$ & $\begin{array}{l}\text { Pre- } \\
\text { intervention; } \\
\text { post } \\
\text { intervention } \\
\text { follow-up on } \\
\text { Week } 8\end{array}$ \\
\hline Effectiveness & $\begin{array}{l}\text { Outcomes of the intervention and } \\
\text { impact on quality of life }\end{array}$ & $\begin{array}{l}\text { Individual level: } \\
\text { Health talk, individual counseling, mobile } \\
\text { phone calls, mobile-phone text messages, } \\
\text { and blood testing for the participants } \\
\text { Organizational level: } \\
\text { Flexible duty roster to facilitate } \\
\text { participation in the program activities } \\
\text { and to the free blood testing provided to } \\
\text { participants }\end{array}$ & $\begin{array}{l}\text { Body weight; BMI; } \\
\text { body fat percentage; } \\
\text { waist circumference; } \\
\text { blood pressure; } \\
\text { fasting serum } \\
\text { glucose level; } \\
\text { fasting lipid profile; } \\
\text { self-reported } \\
\text { changes in lifestyle } \\
\text { pattern; quality of } \\
\text { life }\end{array}$ & $\begin{array}{l}\text { Pre- } \\
\text { intervention; } \\
\text { post } \\
\text { intervention } \\
\text { follow-up on } \\
\text { Week } 8\end{array}$ \\
\hline Adoption & Acceptability of the program & $\begin{array}{l}\text { Individual level: } \\
\text { Booklet, mobile phone calls and mobile } \\
\text { phone text message to support behavioral } \\
\text { changes } \\
\text { Organizational level: } \\
\text { Collaborating with multilevel } \\
\text { management }\end{array}$ & $\begin{array}{l}\text { Participants } \\
\text { demographic } \\
\text { characteristic; } \\
\text { worksite } \\
\text { characteristics; } \\
\text { focus group } \\
\text { interview }\end{array}$ & $\begin{array}{l}\text { Ongoing; } \\
\text { post } \\
\text { intervention } \\
\text { follow-up on } \\
\text { Week } 8\end{array}$ \\
\hline Implementation & Delivery of the interventions & $\begin{array}{l}\text { Individual level: } \\
\text { Health education includes nutritional fact } \\
\text { interpretation, healthy recipes, calorie } \\
\text { calculation, healthy cooking tips, and } \\
\text { BMI interpretation } \\
\text { Organizational level: } \\
\text { Blood testing service by pathological } \\
\text { department; abnormal blood result } \\
\text { counseling by accident and emergency } \\
\text { department; health talk and individual } \\
\text { counseling by dietetic department; } \\
\text { participants were recruited and screened } \\
\text { by trained Advanced Practice Nurse from } \\
\text { the surgical department }\end{array}$ & $\begin{array}{l}\text { Participants } \\
\text { outcome; } \\
\text { participants; } \\
\text { retention rate; focus } \\
\text { group interview }\end{array}$ & $\begin{array}{l}\text { Ongoing } \\
\text { post } \\
\text { intervention } \\
\text { follow-up on } \\
\text { Week } 8\end{array}$ \\
\hline Maintenance & Sustainability of the program & $\begin{array}{l}\text { Individual level: } \\
\text { Reinforce healthy eating habits } \\
\text { Organizational level: } \\
\text { Financial support for program costs }\end{array}$ & $\begin{array}{l}\text { Participants } \\
\text { outcome; } \\
\text { participants; } \\
\text { retention rate; focus } \\
\text { group interview }\end{array}$ & $\begin{array}{l}\text { Post } \\
\text { intervention } \\
\text { follow-up on } \\
\text { Week } 8\end{array}$ \\
\hline
\end{tabular}




\section{References}

[1] Must A, Spadano J, Coakley EH, Field AE, Colditz G, Dietz WH The disease burden associated with overweight and obesity. Jama. 1999 Oct 27;282(16):1523-9.

[2] Moreau M, Valente F, Mak R, Pelfrene E, De Smet P, De Backer G, Kornitzer M. Obesity, body fat distribution and incidence of sick leave in the Belgian workforce: the Belstress study. International journal of obesity. 2004 Apr 1;28(4):57482.

[3] Burton J, World Health Organization. WHO Healthy workplace framework and model: Background and supporting literature and practices.

[4] Conrad KM, Conrad KJ, Parker JE. Job satisfaction among occupational health nurses. Journal of Community Health Nursing. 1985 Sep 1;2(3):161-73.

Goetzel RZ, Henke RM, Tabrizi M, Pelletier KR, Loeppke R, Ballard DW, Grossmeier J, Anderson DR, Yach D, Kelly RK, Serxner S. Do workplace health promotion (wellness) programs work? Journal of Occupational and Environmental Medicine. 2014 Sep 1;56(9):927-34.

[6] Rongen A, Robroek SJ, Van Ginkel W, Lindeboom D, Altink B, Burdorf A. Barriers and facilitators for participation in health promotion programs among employees: a six-month follow-up study. BMC Public Health. 2014 Jun 9;14(1):573.

[7] Hassard J, Muylaert K, Namysl A, Kazenas A, Flaspoler E. Motivation for employers to carry out workplace health promotion: literature review.

Glasgow RE, Vogt TM, Boles SM. Evaluating the public health impact of health promotion interventions: the RE-AIM framework. American journal of public health. 1999 Sep;89(9):1322-7.

Evetts J. The concept of professionalism: Professional work, professional practice and learning. InInternational handbook of research in professional and practice-based learning 2014 (pp. 29-56). Springer Netherlands.

[10] Hall RH. Professionalization and bureaucratization. American sociological review. 1968 Feb 1:92-104.

[11] Bonell C. Evidence-based nursing: a stereotyped view of quantitative and experimental research could work against professional autonomy and authority. Journal of Advanced Nursing. 1999 Jul 1;30(1):18-23.

[12] Foxcroft DR, Cole N. Organisational infrastructures to promote evidence based nursing practice. Cochrane Database of Systematic Reviews. 2000;3.

[13] Robbins SP, Coulter M. Organizational culture and environment. Management. 2009:110-3.

[14] House RJ, Hanges PJ, Javidan M, Dorfman PW, Gupta V, editors. Culture, leadership, and organizations: The GLOBE study of 62 societies. Sage publications; 2004 Apr 29.

Casida JJ, Pinto-Zipp G. Leadership-organizational culture relationship in nursing units of acute care hospitals. Nursing Economics. 2008 Jan 1;26(1):7.
Ejimabo NO. The Influence of Decision Making in Organizational Leadership and Management Activities. Journal of Entrepreneurship \& Organization Management. 2015.

[17] O'Brien MA, Rogers S, Jamtvedt G, Oxman AD, Odgaard-Jensen J, Kristoffersen DT, Forsetlund L, Bainbridge D, Freemantle N, Davis D, Haynes RB. Educational outreach visits: effects on professional practice and health care outcomes. The Cochrane Library. 2007 Jan 1

[18] Cheek J, Gibson T. The discursive construction of the role of the nurse in medication administration: an exploration of the literature. Nursing inquiry. 1996 Jun 1;3(2):83-90.

[19] Carayon P, Hundt AS, Karsh BT, Gurses AP, Alvarado CJ, Smith M, Brennan PF. Work system design for patient safety: the SEIPS model. Quality and Safety in Health Care. 2006 Dec 1;15(suppl 1):i50-8

[20] Wu YK, Chu NF. Introduction of the transtheoretical model and organisational development theory in weight management: A narrative review. Obesity research \& clinical practice. 2015 Jun 30;9(3):203-13.

[21] Gilley A, Gilley JW, McMillan HS. Organizational change: Motivation, communication, and leadership effectiveness. Performance improvement quarterly. 2009 Jan 1;21(4):75-94.

[22] Puhl RM, Heuer CA. Obesity stigma: important considerations for public health. American journal of public health. 2010 Jun;100(6):1019-28.

[23] Ware Jr JE, Kosinski M, Keller SD. A 12-Item Short-Form Health Survey: construction of scales and preliminary tests of reliability and validity. Medical care. 1996 Mar 1;34(3):220-33.

[24] Walker SN, Sechrist KR, Pender NJ. The health-promoting lifestyle profile: development and psychometric characteristics. Nursing research. 1987 Mar 1;36(2):76-81

[25] Kouzes JM, Posner BZ. The leadership practices inventory (LPI): Participant's workbook. John Wiley \& Sons; 2003 May 22

[26] Adams M, Robert G, Maben J. 'Catching up': The significance of occupational communities for the delivery of high quality home care by community nurses. Health:. 2013 Jul;17(4):42238

Foot C, Cornwell J. Improving patients' experiences: an analysis of the evidence to inform future policy development. London: The King's Fund. 2010. 